\title{
Dipilidiose em cães - Relato de caso
}

\author{
$\underline{\text { Daniel Serafim de Andrade Rodrigues }}^{1 *}$; Dalvan Fortaleza Alencar ${ }^{1}$; Brenda Lurian do \\ Nascimento Medeiros $^{1}$
}

${ }^{I}$ Graduando em Medicina Veterinária pela Universidade Federal do Piauí

*Autor para correspondência, E-mail: danielserafimvet@gmail.com

RESUMO: A dipilidiose é uma doença parasitária causada pelo cestóide Dipylidium caninum, que na sua forma adulta parasita o intestino delgado de caninos, felinos e acidentalmente o homem. No estádio larval, o parasito localiza-se na cavidade geral dos hospedeiros intermediários, as pulgas e piolhos. Os cães contraem a doença ao ingerir o hospedeiro intermediário infectado com larvas cisticercóides. Este artigo relata o caso de quatro cães infectados naturalmente por D. caninum atendidos no Hospital Veterinário da Universidade Federal do Piauí.

Palavras chave: Dipylidium caninum, cestóide, cão.

\section{Dipylidiasis in dogs - Case report}

\begin{abstract}
The dipylidiasis is a parasitic disease caused by cestoda Dipylidium caninum, which in its adult parasite form the small intestine of dogs, cats and accidentally man. In the larval stage, the parasite is located in the body cavity of the intermediate hosts, fleas and lice. Dogs contract the disease by eating infected intermediate host with cisticercoides larvae. This article reports the case of four dogs naturally infected by $D$. caninum attended at the Veterinary Hospital of Universidade Federal do Piauí.
\end{abstract}

Keywords: Dipylidium caninum, cestoda, dog.

\section{Introdução}

Vários tipos de cestódeos podem infectar o intestino de cães, sendo que raramente causam uma doença grave. O D. caninum é o cestoide mais comum em cães e gatos, uma vez que a maioria desses animais alimentam-se de comida industrializada e possui acesso restrito às presas naturais diminuindo a incidência de infecção por outros cestódeos (Kahn, 2011; Nelson \& Couto, 2015).

Também chamado de tênia pepino, o $D$. caninum é um cestóide da ordem cyclophyllidea que na sua forma adulta mede de 20 a $60 \mathrm{~cm}$ de comprimento por 2 a $4 \mathrm{~mm}$ de largura e parasita o intestino delgado dos caninos, felinos e acidentalmente $\mathrm{O}$ homem. O estádio larval cisticercóide localiza-se na cavidade geral dos hospedeiros intermediários (pulgas e piolhos). $\mathrm{O}$ ciclo de vida do $D$. caninum envolve a ingestão de pulgas infectadas com larvas cisticercóides pelos cães. Os cães infectados eliminam as proglótides grávidas que possuem forma de semente de pepino em suas fezes, e essas proglótides no ambiente são consumidas por larvas de pulga (Fortes, 2004, Wani et al., 2015).

Possui distribuição cosmopolita no cão doméstico (Canis familiaris) e gatos domésticos (Felis catus). Eventuais casos de infecção em seres humanos, particularmente em crianças, podem ocorrer. Este parasito também infecta os carnívoros selvagens prevalentemente nas famílias Canidae e Hyaenidae (East et al., 2013).

Embora a literatura cite o D. caninum como o cestóide mais comum em cães, sua incidência parece ser baixa. Alves et al. (2006) e Oliveira et al. (2010) observaram, respectivamente, uma prevalência de infecção por $D$. caninum de $0,3 \%$ em cães domiciliados e de $1 \%$ em cães errantes em Goiânia-GO. Santos \& Castro (2006) observaram uma prevalência de $2,4 \%$ do parasito em cães domiciliados em Guarulhos-SP. Blazius et al. (2005) constataram uma incidência de 1,9\% em cães errantes da cidade de Itapema-SC. Leite et al. (2007), em Curitiba-PR, observaram uma prevalência de $0,77 \%$. Farias et al. (2013) 
constataram uma taxa de infecção de $1,9 \%$ no município de Bom Jesus-PI.

Os sinais mais comum em cães e gatos infectados é uma irritação anal associada a segmentos (proglótides) que são eliminados sobre a área onde o animal se arrastou. Tipicamente, o proprietário vê os segmentos de cestoides móveis nas fezes e requisita um tratamento (Nelson \& Couto, 2015).

\section{Descrição dos casos}

Foram atendidos no Hospital Veterinário da Universidade Federal do Piauí, quatro cães SRD (sem raça definida), com sinais de diarréia, emagrecimento e prurido anal. Em todos os casos, segundo os proprietários, os animais eliminavam nas fezes larvas semelhante a sementes de pepino e com presença de mobilidade.
Caso 1: Fêmea, SRD, 5 anos de idade e peso corporal de $8,3 \mathrm{~kg}$.

Caso 2: Macho, SRD, 4 anos e 5 meses de idade, peso corporal de $20 \mathrm{~kg}$.

Caso 3: Macho, SRD, 10 anos de idade e peso corporal de 19,1 kg.

Caso 4: Macho, SRD, 9 anos e 2 meses, peso corporal de $13,4 \mathrm{~kg}$.

\section{Discussão}

Durante a anamnese foi relatado o histórico de infecção por pulgas e ao exame físico foi detectado a presença de pulgas nos casos 1 e 3 (Figura 1). Após acompanhamento, foi observado na defecação, fezes com presença de proglotides, diarréicas e às vezes com rajadas de sangue (Figura 2).
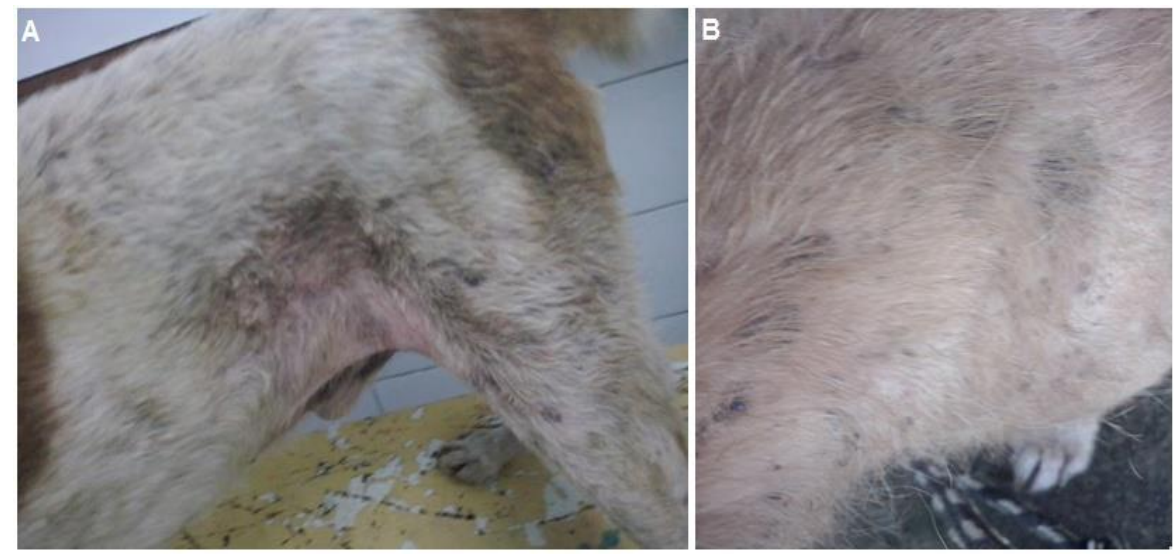

Figura 1. Cão apresentando infestação por pulga (áreas escuras sobre a pelagem) com dermatite alérgica na região de flanco e inguinal (A). Cadela com infestação por pulgas (B).
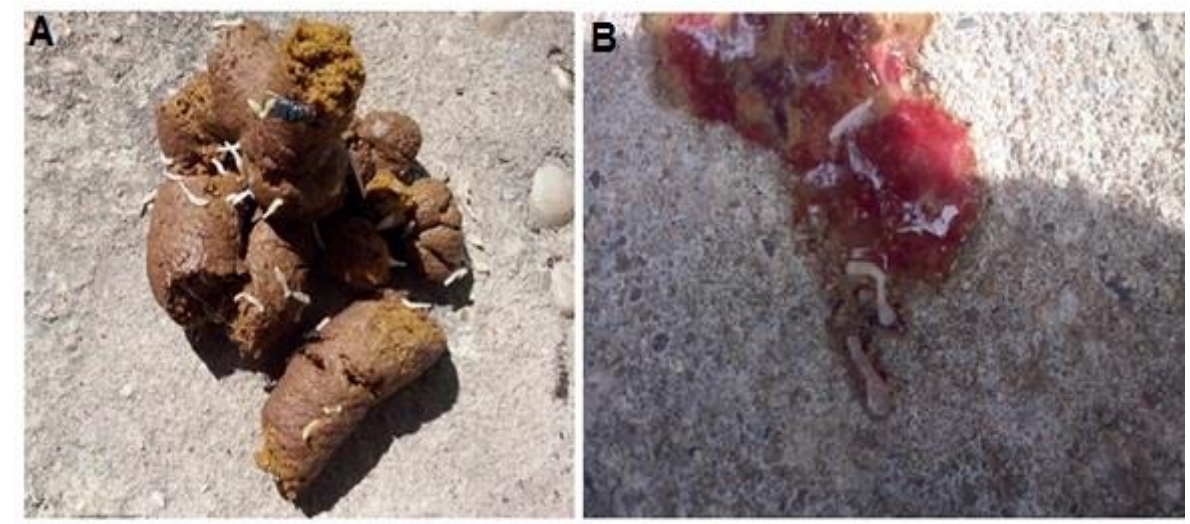

Figura 2: Presença de proglotides de Dipylidium caninum distribuidas sobre as fezes de um dos cães (A). Presença de proglotides de D. caninum em formato de semente de pepino em fezes diarréicas com rajadas de sangue (B).

Amostras das fezes foram coletadas e enviadas para o laboratório de doenças parasitárias do Hospital Veterinário da
Universidade Federal do Piauí, onde foi feita a confirmação da infecção por Dipylidium caninum 
por meio da identificação dos ovos do parasito através do método de Hoffman.

Segundo Nelson \& Couto (2015) o cão é infectado quando ingere um hospedeiro intermediário infectado, como as pulgas e piolhos. Todos os quatro animais deste relato apresentavam histórico de infestação por pulgas, o que lhe tornavam suscetíveis a infecção pelo $D$. caninum.

Para Kahn (2011) infecções por esse parasito raramente causam uma doença grave e segundo Nelson \& Couto (2015) os sinais mais comum são irritação anal associada a segmentos que são eliminados sobre a área onde o animal se arrastou. Todavia, Fortes (2004) ressalta que em infecções maciça pode ocorrer inflamação, invaginação e obstrução intestinal.

Os animais do caso 1 e 3 também foram diagnosticados com infecção por Leishmania sp, o que lhe tornaram mais vulneráveis à infecção por D. caninum, uma vez que a leishmaniose lhe causaram imunossupressão. Nestes animais os sintomas clínicos do parasitismo por $D$. caninum se mostraram mais intenso, como prurido anal, dificuldades de defecação, diarréia com rajadas de sangue, e constante eliminação de proglotides. Os animais do caso 2 e 4 apresentaram como sinais apenas o prurido anal e eliminação ocasional de proglotides.

Após o diagnóstico, todos os animais foram tratados para a infecção por $D$. caninum com uso de Prazinquantel (Drontal Plus ${ }^{\circledR}$ ), 1 comprimido $/ 10 \mathrm{~kg}$, por via oral e em dose única. Para o caso 01 e 03 foi feito concomitante o tratamento para a infestação por pulgas no animal com administração por via tópica de $6 \mathrm{mg} / \mathrm{kg}$ de selamectina e pulverização do ambiente de convívio do animal com uso de Amitraz 12,5\%.

Após o tratamento, os animais não manifestaram mais os sintomas da doença, indicando para a cura da infecção pelo parasito e demonstrando a eficácia do protocolo terapêutico.

\section{Conclusão}

A infecção por Dipylidium caninum pode acarretar desconforto ao animal como o prurido anal, distúrbios intestinais como diarreia, e perda de peso. Contudo, o tratamento medicamentoso é eficaz contra o parasito e deve ser associado ao combate dos hospedeiros intermediários.

\section{Referências Bibliográficas}

Alves, O. F., Gomes, A. G. \& Silva, A. C. (2006). Ocorrência de enteroparasitos em cães do município de Goiânia, Goiás: comparação de técnicas de diagnóstico. Ciência Animal Brasileira, 6, 127-133.

Blazius, R. D., Emerick, S., Prophiro, J. S., Romão, P. R. T. \& Silva, O. S. (2005). Ocorrência de protozoários e helmintos em amostras de fezes de cães errantes da cidade de Itapema, Santa Catarina. Revista da Sociedade Brasileira de Medicina Tropical, 38, 73-74.

East, M. L., Kurze, C., Wilhelm, K., Benhaiem, S. \& Hofer, H. (2013). Factors influencing Dipylidium sp. infection in a free-ranging social carnivore, the spotted hyaena (Crocuta crocuta). International Journal for Parasitology: Parasites and Wildlife, 2, 257-265.

Farias, A. N. S., Silva, M., Oliveira, J. B. S., Rocha, L. B. \& Santos, K. R. (2013). Diagnóstico de parasitos gastrointestinais em cães do município de Bom Jesus, Piauí. Revista Acadêmica, Ciências Agrárias e Ambientais, 11, 431-435.

Fortes, E. (2004). Parasitologia veterinária, 4 edn. Editora ícone, São Paulo.

Kahn, C. M. Manual Merck: Saúde animal. (2011). 1 ed. São Paulo: Roca, 1192 p.

Leite, L. C., Cirio, S. M., Navarro-Silva, M. A., Zadorosnei, A. C. B., Luz, E., Marinoni, L. P., Leite, S. C. \& Lunelli, D. (2007). Ocorrência de endoparasitas em amostras de fezes de cães (Canis familiaris) da região metropolitana de CuritibaParaná-Brasil. Estudos de Biologia, 29, 319-326.

Nelson, R. W. \& Couto, C. G. (2015). Medicina interna de pequenos animais. 5 ed. Rio de Janeiro: Elsevier, 1474p.

Oliveira, V. S. F., Melo, D. P. G., Fernandes, P. R., Schulze, C. M. B., Guimarães, M. S. \& Silva, A. C. (2010). Ocorrência de helmintos gastrintestinais em cães errantes na cidade de Goiânia-GO. Revista de Patologia Tropical, 38, 279-283.

Wani, Z., Allaie, I., Shah, B., Raies, A., Athar, H. \& Junaid, S. (2015). Dipylidium caninum infection in dogs infested with fleas. Journal of Parasitic Diseases, 39, 73-75.

\section{Recebido em Dezembro 14, 2015}

Aceito em Janeiro 12, 2016

License information: This is an open-access article distributed under the terms of the Creative Commons Attribution License, which permits unrestricted use, distribution, and reproduction in any medium, provided the original work is properly cited. 